Original Article

\title{
Anterior Cervical Corpectomy with Cage Fixation for Cervical Spondylotic Myelopathy
}

\author{
Muhammad Anwar Ullah', Muhammad Usman', Faheem Ullah Khan ${ }^{\mathbf{2}}$, Jehanzeb ${ }^{\mathbf{1}}$, Abdul Jalal ${ }^{\mathbf{1}}$ \\ ${ }^{1}$ Department of Neurosurgery, Lady Reading Hospital MTI, Pakistan \\ ${ }^{2}$ Department of Pharmacy, Abasyn University, Peshawar - Pakistan
}

\section{ABSTRACT}

Objective: This study aimed to report the clinical outcome of anterior cervical corpectomy with cage fixation in patients with cervical spondylotic myelopathy.

Material and Methods: This observational retrospective study included 36 patients from the Neurosurgery department of Lady Ready Hospital MTI, Peshawar from 2014 January to 2015 December. After performing surgery, the patients were followed up for six months for neurological outcome and various post-operative complications such as infection, transient recurrent laryngeal palsy, screw displacement and improvements in paresthesias and gait ataxia.

Results: Most of the patients have no post-operative complications. Seventy-five percent $(n=27)$ of patients reported an immediate improvement in paresthesia and fine hand movements and gait. The major reported complications were implant failure (5.55\%) and recurrent laryngeal nerve transient palsy in two patients (5.55\%) each.

Conclusion: In patients with cervical spondylotic myelopathy, with anterior compression, cervical corpectomy with cage fixation is less invasive and an effective procedure with acceptable outcomes.

Keywords: Cervical Cage, Cervical fixation, Spondylotic Myelopathy, Corpectomy.

\section{Corresponding Author: Muhammad Usman}

Neurosurgery Department, Lady Reading Hospital,

Peshawar - Pakistan

Email: drusman387@yahoo.com

Date of Submission: 12-02-2021

Date of Revision: 05-03-2021

Date of Online Publishing: 31-03-2021

Date of Print: 31-03-2021

DOI: 10.36552/pjns.v25i1.529

\section{INTRODUCTION}

Cervical spondylotic myelopathy (CSM) is an agerelated ailment of the spinal cord. CSM is a symptomatic clinical disorder due to compression of the spinal cord owing to degenerative disease, which can be observed at the radiological examination. CSM leads to the stenosis of the cervical spinal canal with or without any signs and symptom. ${ }^{1}$ CSM is one of the most common reasons for the elderly dysfunction of the spinal cord and mostly manifest long-tract disabilities such as quadriparesis and non-traumatic spastic 
paraparesis due to compression of the spinal cord. $^{2,3}$ Other clinical disorders of CSM includes difficulty in gait or balance, loss of manual precision, clumsiness, sensory changes, urinary complaints, motor weakness and abnormal reflexes. Spinal instability associated with CSM can be identified by appropriate imaging techniques such as flexion-extension views and plan static radiographs. ${ }^{4}$ Even though CSM is a prevalent disorder, its treatment is still controversial in terms of non-surgical versus surgical treatment, timings of surgery, surgical indications, surgical approach, and surgery type. Earlier studies advocate that neurological deterioration is most common in advanced stages of CSM. ${ }^{5}$

A study comparing surgical and non-surgical treated patients reported significant deteriorating conditions of the non-surgically treated patients with worsening neurologic symptoms while surgically treated patients showed a significant overall improvement in daily activities with less pain as observed in neurologic symptoms. ${ }^{6}$ Another study ${ }^{7}$ suggested better outcomes for surgically treated CSM patients and concluded that surgery is a suitable option for clinically worsen patients having a spinal cord transverse area of less than $70 \mathrm{~mm}^{2}$ Several authors suggest surgical treatment as a better option but still, it remains controversial. Anterior, posterior and 360-degree approach (combined anterior and posterior), has been recommended for multilevel CSM patients. ${ }^{8}$ Generally, the anterior surgical approach has been preferred for patients with level 1 or 2 CSM and the posterior approach is reserved for patients having multilevel CSM.9,10 The posterior approach has been reported to have a high level of complications compared to the anterior approach by some authors. ${ }^{11}$ The majority of surgeons prefer the anterior approach for single-level CSM. Anterior approaches to the cervical spine, weather corpectomy or discectomy with fusion are efficient surgical techniques with their distinctive pros and cons. These anterior approaches capitulate improved results in term of blood loss, infection, and operative time and carries lower rates of pseudoarthrosis as well as diminish the risk of spinal cord injury. ${ }^{12,13}$

In a study done by Khalid et $\mathrm{al}^{14}$ showed that treatment of patients of subaxial CSM, with corpectomy and bone grafting, had significantly improved neurological outcomes.

The current study was designed to evaluate the clinical outcome and complications of anterior cervical corpectomy with cage fixation for the treatment of cervical spondylotic myelopathy. Our results will give some insight into the outcomes of surgical treatment of CSM in our region.

\section{MATERIAL AND METHODS}

\section{Study Design and Study Settings}

This observational retrospective study was carried out in the Neurosurgery department of Lady Reading Hospital, MTI Peshawar for a period of two (02) years, from January 2014 to December 2015. Ethical approval for this study was granted by the hospital's research and ethical committee. All the patients admitted to the Neurosurgery department and fulfilling the inclusion criteria were enrolled. The sampling technique was nonprobability consecutive sampling. The objective and benefits of the study were made clear to the patients, in the language they understood, and informed written consent was taken before the start of the study. There were initially 64 patients, but 36 met the inclusion criteria and were included in this study.

\section{Inclusion Criteria}

The inclusion criteria included all patients of either sex who have cervical spondylotic myelopathy and underwent anterior cervical corpectomy with cage fixation. 


\section{Exclusion Criteria}

All those patients were excluded from this study who have radiculo-myelopathy, unfit or unwilling for the surgery.

\section{Data Collection}

Demographics including name, age, address, and gender of all the patients included in the study were recorded on a predesigned proforma. Clinical record, postoperative complications, radiological data, and clinical condition before and after the surgery was also recorded.

\section{Data Analysis}

The data was analyzed by using SPSS version 20 . The quantitative data like age was presented as mean \pm SD while, for categorical variables such as gender and surgical complications (screw displacement, implant subsidence, infections, transient dysphagia, transient, laryngeal nerve paresis and pre-vertebral hematoma), frequencies and percentages were calculated.

\section{RESULTS}

\section{Gender Incidence}

Out of a total of 36 patients, 23 (63.88\%) were male and 13 (36.11\%) were female.

\section{Age Range}

The age of the patients ranges from $34-72$ years with a mean of 54.4 years.

\section{Clinical Presentation}

The common most clinical symptom was dysesthesia and paresthesia (82\%), which was followed by weakness of the limbs and ataxic gait
(Table 1). Duration of the disease ranges from 3 months to 9 years. Paresthesias showed dramatic and immediate improvement in 27 (75\%) patients, whereas there was a substantial improvement in fine movements of hands, gait, and other characters in follow-up (Table 1).

\section{Post-operative Complications}

The major surgical complications were implant subsidence followed by temporary recurrent laryngeal nerve palsy (Table 2). For implant failure, re-do surgery was done. Post-operatively, cervical lordosis with alignment was up to the mark in 33 patients. Follow-up of the patients was done in OPD at intervals of 2 weeks, 2 months, and 6 months.

\section{DISCUSSION}

Successful treatment of a disease is based on a clear understanding of the natural history and pathophysiology of the disease under treatment. A clinical study helps in collecting reliable data, planning appropriate management, and anticipating the known complications. ${ }^{15}$ The exact 
incidence and prevalence of CSM are still unknown but this disease is caused by the degeneration of the spinal cord and the geriatric population is most commonly affected. CSM being a multilevel disease in the majority of cases, the most common level for spinal cord compression is C5 and C6. ${ }^{16}$ Surgery is generally advocated for CSM as it changes the natural history and overall prognosis of the patient. Surgical approach; either anterior or posterior, includes decompression of the neural structures (spinal cord and nerve roots), height restoration, reconstruction of the lordosis, and stabilization of the spine to check further degradation of the affected level. ${ }^{17}$ Oh et al. reported ACDF as a superior approach compared with ACCF in terms of multiple variables, like; operative time, blood loss, and radiological results in patients with 2level CSM. $^{18}$ Another study reports ACDF as a technique with less bleeding, short surgery time, better radiological outcomes compared with ACCF. ${ }^{19}$ Another study also reported ACDF as superior in terms of stay at the hospital, blood loss, and increased cervical lordosis. ${ }^{20}$ On the other hand, studies done by other researchers ${ }^{21,22}$ documented that there is no significant advantage of ACDF over the ACCF in patients for multi-level CSM. Another very important study ${ }^{23}$ suggested that the two surgical procedures generate similar outcomes, in terms of cervical lordosis, graft subsidence, adjacent level disease, and sagittal alignment.

According to our retrospective study of 36 patients, $86 \%$ of patients showed immediate improvement in paresthesia, hand movement, and gait problems. Literature shows up to $94 \%$ improvement after the surgery for cervical radiculopathy and/or myelopathy. ${ }^{24,25}$ This difference might be due to the fact that in our study sample size is limited.

Surgical complications observed upon follow up were screw displacement (2.7\%), transient recurrent laryngeal nerve paresis (5.5\%), implant subsidence (5.5\%), esophageal fistula (2.8\%), infection (2.8\%) and prevertebral hematoma (2.8\%). Instrument associated complications after multilevel corpectomies are very usual. ${ }^{21}$

The surgical and instrument-related complications rate in this study was $11 \%$, this is in agreement with the data published in the literature with complications rates ranging from 6 to $9.5 \% .^{22}$ We routinely used the operating microscope. Furthermore, the single operating team, comprising of 4 experienced neurosurgeons, operate upon all the cases and the cage which we use in all our patients was the titanium cage. The surgeon's experience is an important factor in reducing intraoperative damage. Having said that in the current study, however, there was no permanent neurological injury. The transient hoarseness was treated expectantly and resolved within 6 months.

Post-operatively, cervical curve and alignment were satisfactory in 33 patients. These major findings are compatible with the literature..$^{20,24,25,26}$

There are few limitations of our study, like the sample size was small and it is a single-center trial. But this study paves the foundation for further research in this field.

\section{CONCLUSION}

In patients with cervical spondylotic myelopathy, with anterior compression of more than 1 level, cervical corpectomy with cage fixation is less invasive and an effective procedure with acceptable outcomes.

\section{REFERENCES}

1. Boogaarts HD, Bartels RH. Prevalence of cervical spondylotic myelopathy. European Spine Journal, 2015; 24 (2): 139-41.

2. Raj-D-Rao BLC, Albert TJ, Bono CM, Marawar SV, Poelstra KA, Eck JC. Degenerative cervical spondylosis: clinical syndromes, pathogenesis, and management," The Journal of Bone and Joint Surgery, 2007; 89 (6): 1360-78. 
3. Akiyama-HGaM. What is the optimal method of managing a patient with cervical myelopathy? In: Wright JG, editor. Evidence based orthopedics. Toronto, Ontario, Canada: Saunders; 2008.

4. Yalamanchili MJV, Chaudhary SB. Cervical Spondylotic Myelopathy: Factors in Choosing the Surgical Approach. Advances in Orthopedics. 2012, Article ID 783762, 2012. https://doi.org/10.1155/2012/783762.

5. Symon L, Lavender P. The surgical treatment of cervical spondylotic myelopathy. Neurology, 1967; 17 (2): 117.

6. Sampath $P$, Bendebba $M$, Davis JD, Ducker TB. Outcome of patients treated for cervical myelopathy: a prospective, multicenter study with independent clinical review. Spine, 2000; 25 (6): 670-6.

7. Kadanka ZMM, Bednarik J, Smrcka V, Chaloupa R, Dusek L. Predictive factors for spondylotic cervical myelopathy treated conservatively or surgically. European Journal of Neurology, 2005; 12: 55-63.

8. Ghogawala ZCJ, Benzel EC. Ventral versus dorsal decompression for cervical spondylotic myelopathy: surgeons' assessment of eligibility for randomization in a proposed randomized controlled trial: results of a survey of the Cervical Spine Research Society. Spine, 2007; 32: 429-36.

9. Kawakami MTT, Lwasaki H. A comparative study of surgical approaches for cervical compressive myelopathy. Clin Orthop Relat Res. 2000; 381: 12936.

10. Hillard VHAR. Surgical management of cervical myelopathy: indications and techniques for multilevel cervical discectomy. Spine J. 2006; 6 (6): S242-S51.

11. Shamji MFCC, Pietrobon R. Impact of surgical approach on complications and resource utilization of cervical spine fusion: a nationwide perspective to the surgical treatment of diffuse cervical spondylosis. Spine J. 2009; 9: 31-8.

12. Burkhardt JKMA, Marbacher S, Dolp PA, Fekete TF, Jeszenszky D, Porchet F. A comparative effectiveness study of patient-rated and radiographic outcome after 2 types of decompression with fusion for spondylotic myelopathy: anterior cervical discectomy versus corpectomy. Neurosurg Focus, 2013; 35 (1): E4.

13. Guan LHY, Yang JC, Zhou LJ, Chen XL. Anterior cervical discectomy and fusion may be more effective than anterior cervical corpectomy and fusion for the treatment of cervical spondylotic myelopathy. BMC Musculoskelet Disord. 2015; 16: 29.

14. Khalid M, Farooq U, Ahmed E, Khaleeq S, Khaleequz-Zaman. Surgical Outcome of Corpectomy, Bone Grafting and Caspar Plating in Non-Traumatic Cervical Spine Disease. J Postgrad Med Ins. 2017; 31 (3): 304-9.

15. Chibbaro LBS, Carnesecchi S, Marsella M, Pulera F, Serino D, Gagliardi R. Anterior cervical corpectomy for cervical spondylotic myelopathy: Experience and surgical results in a series of 70 consecutive patients. Journal of Clinical Neuroscience, 2006; 13: 233-8.

16. Northover J, Wild J, Braybrooke J, Blanco J. The epidemiology of cervical spondylotic myelopathy. Skeletal Radiology, 2012; 41 (12): 1543-6.

17. Lin Q, Zhou X, Wang $X$, Cao P, Tsai N, Yuan W. A comparison of anterior cervical discectomy and corpectomy in patients with multilevel cervical spondylotic myelopathy. European Spine Journal, 2012; 21 (3): 474-81.

18. Oh MC, Zhang HY, Park JY, Kim KS. Two-level anterior cervical discectomy versus one-level corpectomy in cervical spondylotic myelopathy. Spine, 2009; 34 (7): 692-6.

19. Huang ZY, Wu AM, Li QL, Lei T, Wang KY, Xu HZ, et al. Comparison of two anterior fusion methods in two-level cervical spondylosis myelopathy: a meta-analysis. BMJ Open, 2014; 4 (7): e004581.

20. Han YC, Liu ZQ, Wang SJ, Li LJ, Tan J. Is anterior cervical discectomy and fusion superior to corpectomy and fusion for treatment of multilevel cervical spondylotic myelopathy? A systemic review and meta-analysis. PLoS One, 2014; 9 (1): e87191.

21. Fernyhough JC, White JI, LaRocca H. Fusion rates in multilevel cervical spondylosis comparing allograft fibula with autograft fibula in 126 patients. Spine, 1991; 16: S561-S564.

22. Lin $Q$, Zhou $X$, Wang $X$. A comparison of anterior cervical discectomy and corpectomy in patients with multilevel cervical spondylotic myelopathy. Eur Spine J. 2012; 21 (3): 474-481.

23. Park Y, Maeda T, Cho W, Riew KD. Comparison of anterior cervical fusion after two-level discectomy 
or single-level corpectomy: sagittal alignment, cervical lordosis, graft collapse, and adjacent-level ossification. Spine J. 2010; 10 (3): 193-9.

Doi: 10.1016/j.spinee.2009.09.006. Epub 2009 Oct 21. PMID: 19850532.

24. Lau D, Chou D, Mummaneni PV. Two-level corpectomy versus three-level discectomy for cervical spondylotic myelopathy: a comparison of perioperative, radiographic, and clinical outcomes. J Neurosurg Spine, 2015; 23 (3): 280-9.

Doi: 10.3171/2014.12.SPINE14545. Epub 2015 Jun 19. PMID: 26091438.
25. Hessler C, Boysen K, Regelsberger J, Vettorazzi E, Winkler $D$, Westphal M. Patient satisfaction after anterior cervical discectomy and fusion is primarily driven by relieving pain. Clin J Pain, 2012; 28 (5): 398-403.

26. Burkhardt JK, Mannion AF, Marbacher S, Dolp PA, Fekete TF, Jeszenszky $D$, et al. A comparative effectiveness study of patient-rated and radiographic outcome after 2 types of decompression with fusion for spondylotic myelopathy: anterior cervical discectomy versus corpectomy. Neurosurg Focus, 2013; 35 (1): E4. Doi: 10.3171/2013.3.FOCUS1396. PMID: 23815249.

\section{Additional Information}

Disclosures: Authors report no conflict of interest.

Ethical Review Board Approval: The study was conformed to the ethical review board requirements.

Human Subjects: Consent was obtained by all patients/participants in this study.

\section{Conflicts of Interest:}

In compliance with the ICMJE uniform disclosure form, all authors declare the following:

Financial Relationships: All authors have declared that they have no financial relationships at present or within the previous three years with any organizations that might have an interest in the submitted work.

Other Relationships: All authors have declared that there are no other relationships or activities that could appear to have influenced the submitted work.

\section{AUTHORS CONTRIBUTIONS}

\begin{tabular}{|l|l|l|}
\hline Sr.\# & Author's Full Name & Intellectual Contribution to Paper in Terms of: \\
\hline 1. & Muhammad Anwar Ullah & Study design and methodology. \\
\hline 2. & Muhammad Usman & Paper writing, referencing, and data calculations. \\
\hline 3. & Faheem Ullah Khan & Data collection and calculations \\
\hline 4. & Jehanzeb & Analysis of data and interpretation of results etc. \\
\hline 5. & Abdul Jalal & Literature review and manuscript writing \\
\hline
\end{tabular}

